\title{
A preliminary study of MMP-9 and SCD40L in patients with coronary slow flow
}

\author{
Xiaobing Zhang ${ }^{1}$, Jiandong Ding ${ }^{2}$, Siliang Xia ${ }^{1}$ \\ ${ }^{1}$ Cardiology Department, Nanjing Jiangbei People's Hospital, Nanjing, China; ${ }^{2}$ Cardiology Department, Zhongda Hospital, Southeast University, \\ Nanjing, China \\ Contributions: (I) Conception and design: All authors; (II) Administrative support: All authors; (III) Provision of study materials or patients: All \\ authors; (IV) Collection and assembly of data: All authors; (V) Data analysis and interpretation: All authors; (VI) Manuscript writing: All authors; (VII) \\ Final approval of manuscript: All authors. \\ Correspondence to: Siliang Xia. Cardiology Department, Nanjing Jiangbei People’s Hospital, Nanjing, China. Email: XSL813@163.com.
}

Background: To explore the relationship between coronary slow flow (CSF) and both matrix metalloproteinase-9 (MMP-9) and soluble cluster of differentiation 40 ligand (sCD40L).

Methods: Between July 2016 and September 2019, 80 patients suspected of having coronary heart disease due to chest tightness or other symptoms of chest pain and discomfort were admitted to Nanjing Jiangbei People's Hospital and, following a coronary angiography, were diagnosed as having CSF. These patients were assigned to the coronary slow flow phenomenon (CSFP) group. The control group, or normal coronary flow (NCF) group, consisted of 80 patients with normal coronary angiography results. Following group assignment, enzyme-linked immunosorbent assays (ELISAs) were used to measure and compare the serum levels of sCD40L and MMP-9 between the two groups.

Results: Serum levels of sCD40L and MMP-9 in the CSFP group were significantly higher than those in the NCF group $(\mathrm{P}<0.05)$. Additionally, serum levels of adhesion molecules and C-reactive protein $(\mathrm{CRP})$ in the CSFP group were significantly higher than those in NCF group $(\mathrm{P}<0.05)$. There was a positive correlation observed between sCD40L levels and adhesion molecule levels in the CSFP group, however, there was no such correlation observed in the NCF group. The CSFP group also had a significantly higher corrected TIMI frame count (CTFC) compared with the NCF group $(\mathrm{P}<0.05)$.

Conclusions: Serum MMP-9 levels were higher in patients with CSF, and MMP-9 levels were positively correlated with CTFC. This suggests that chronic inflammation may play a role in CSF pathogenesis and that atherosclerotic plaques may be present in the coronary arteries of CSF patients. Additionally, serum levels of sCD40L, adhesion molecules, and CRP were higher in CSF patients, and CRP levels were positively correlated with CTFC. Adhesion molecule expression is promoted by sCD40L. Increased levels of sCD40L may therefore promote the development of CSF.

Keywords: Matrix metalloproteinase-9 (MMP-9); soluble cluster of differentiation 40 ligand (sCD40L); coronary slow flow phenomenon (CSFP)

Submitted Sep 24, 2020. Accepted for publication Jan 11, 2021.

doi: 10.21037/apm-20-2271

View this article at: http://dx.doi.org/10.21037/apm-20-2271

\section{Introduction}

The coronary slow flow phenomenon (CSFP) is characterized by delayed distal blood flow (1) that occurs despite coronary angiography showing no coronary lesions (2-4). Before a diagnosis of coronary slow flow (CSF) can be made, other potential causes must first be excluded. These include medical conditions, such as severe coronary artery stenosis, coronary artery spasm, and gas embolism, as well medical treatments that might produce this phenomenon, including coronary angioplasty and thrombolytic therapy 
$(5,6)$. Patients with CSF experience unexplained recurrent chest pain symptoms (7-9). Myocardial ischemia and acute coronary syndrome can occur in patients with severe CSF $(10,11)$, which results in a higher incidence of sudden death caused by acute myocardial infarction and ventricular arrhythmia among these patients (12-14).

To investigate the relationship between CSF and both matrix metalloproteinase-9 (MMP-9) and soluble cluster of differentiation 40 ligand (sCD40L), MMPS is a zincand calcium-dependent peptide chain endonuclease, of which MMP-9 is an important collagenase in the MMPS family. After MMP-9 is activated by the substrate, it can decompose various extracellular matrix protein components of the vascular basement membrane, leading to increased decomposition of atherosclerotic plaque and increased permeability of the vascular barrier. Relevant studies have shown that serum sCD40L is an inflammatory transmembrane protein that participates in the occurrence of inflammatory reactions and plays an important role in the occurrence of cardiovascular diseases.

We retrospectively analyzed the medical records of 80 patients that exhibited CSFP (the CSFP group) and 80 patients with normal coronary flow (the NCF group) that were admitted to Nanjing Jiangbei People's Hospital between July 2016 and September 2019 for chest tightness or other related chest pain symptoms. These patients were suspected of having coronary heart disease and were diagnosed by coronary angiography. We compared serum levels of MMP-9 and sCD40L between the CSFP group and the NCF group, and the relationships between CSF and both MMP-9 and sCD40L were discussed.

We present the following article in accordance with the MDAR reporting checklist (available at http://dx.doi. org/10.21037/apm-20-2271).

\section{Methods}

\section{General information}

We retrospectively analyzed patients suspected of having coronary heart disease due to chest tightness or other symptoms of chest pain or discomfort. These patients were admitted to our hospital for diagnosis by coronary angiography between July 2016 and September 2019. Of these patients, 80 with CSF and 80 without CSF were assigned to the CSFP and NCF groups, respectively.

The CSFP group comprised 35 males and 45 females aged between 30 and 80 years. The average age was
$54.19 \pm 9.20$ years. The NCF group comprised 46 males and 34 females aged between 35 and 75 years. The average age was $50.01 \pm 7.80$ years. There was no significant difference in either age or sex between the two groups $(\mathrm{P}>0.05)$. This study was approved by the Ethics Committee of Nanjing Jiangbei People's Hospital (IRB-TY-2016-78) and all participants signed the informed consent. All procedures performed in this study involving human participants were in accordance with the Declaration of Helsinki (as revised in 2013).

The inclusion criteria of our study were as follows: (I) patients without other inflammatory diseases; (II) patients that have not undergone percutaneous coronary intervention; (III) patients that agreed to sign informed consent; and (IV) patients with complete clinical data.

\section{Preprocedural medication}

The patients in this study were admitted to hospital with suspected coronary heart disease and given medication prior to receiving a coronary angiography. Aspirin and clopidogrel were administered to the patients: $300 \mathrm{mg}$ of aspirin and $300 \mathrm{mg}$ of clopidogrel were given as initial doses, followed by daily doses of $100 \mathrm{mg}$ of aspirin and $75 \mathrm{mg}$ of clopidogrel. All patients in this study were examined by coronary angiography $1-2$ days following their initial doses of medication.

\section{Coronary angiography}

Coronary angiography was performed on all study participants after they received preprocedural medication. Routine projection positions were used throughout this process: when the flow of the right coronary artery was investigated, left anterior oblique cranial projection was used; when the anterior descending branch was investigated, right anterior oblique caudal projection was used; and when the circumflex branch was investigated, left anterior oblique caudal projection was used. Variations on the above projection positions were used depending on the circumstances of the individual patients. If structures overlapped or the contrast medium was not clear enough, the projection angle was adjusted. Coronary flow velocity was determined by corrected TIMI frame count (CTFC); TIMI grading was used to evaluate coronary blood flow velocity, and CTFC was used to quantitatively evaluate coronary blood flow velocity. Image information was collected at 30 frames per second, and the contrast medium 
used was iopamidol. The contrast medium was injected at $3-5 \mathrm{~mL} / \mathrm{s}$ for the left coronary angiography and at $2-3 \mathrm{~mL} / \mathrm{s}$ for the right coronary angiography. The first frame was counted as the time when contrast medium filled the arterial opening in the direction of blood flow. The last frame used in the TIMI frame count for the right coronary artery was the first frame used for the first branch of the posterior left ventricular artery collateral branch; the last frame for the circumflex branch was the first frame when the contrast medium reached the distal bifurcation of the blunt marginal branch; and the last frame for the anterior descending branch was the first frame when the contrast medium reached the "eight" bifurcation of the distal apex of the anterior descending branch. The frame counts were carried out by professional personnel. Clinically normal flow velocity for the anterior descending branch is $36.2 \pm 2.6$ frames (corrected to $21.1 \pm 1.5$ frames); normal flow velocity for the circumflex branch is $22.2 \pm 4.1$ frames; and normal flow velocity for the right coronary artery is $20.4 \pm 3.0$ frames. If the CTFC is found to be two standard deviations from the normal blood flow velocity values when images are collected at the normal speed, the coronary artery blood flow is determined to be the three-tube frame count.

\section{Blood sample collection}

After admission to hospital, all patients underwent routine electrocardiogram (ECG) examination. A volume of $4 \mathrm{~mL}$ fasting venous blood was taken from each patient, mixed evenly at $4{ }^{\circ} \mathrm{C}$, then centrifuged at $2,500 \mathrm{r} / \mathrm{min}$ for 10 minutes. The serum was sealed, packed in labeled test tubes, and stored at $-20{ }^{\circ} \mathrm{C}$. Detection assays were carried out within a month of the serum samples being stored. When the samples were required, they were thawed in $37^{\circ} \mathrm{C}$ water. Blood lipid levels were also detected from the samples. The main detection indexes were low density lipoprotein (LDL), high density lipoprotein (HDL), triglyceride (TG), and total cholesterol (TC). These were measured using an automatic biochemical analyzer.

\section{Detection of serum sCD40L}

Serum sCD40L levels were detected using the enzymelinked immunosorbent assay (ELISA); these procedures were carried out in strict accordance with the ELISA kit instructions. This assay was carried out for all serum samples, and the main steps were as follows. A serum sample and a standard substance with a dilution ratio of
1:100 were diluted into detection well plates, $0.3 \mathrm{~mL}$ of each added to each well. One well was left empty. Prior to this, the serum sample was thawed in $37^{\circ} \mathrm{C}$ water for 3-5 minutes. After washing the wells, chromogenic solution was added and a full reaction allowed to carry out for 3-5 minutes. Optical density at $450 \mathrm{~nm}$ was then determined by spectrophotometry, and the serum concentration of sCD40L was determined by drawing a standard curve.

\section{Detection of cell adhesion factors}

The cell adhesion factors investigated were intercellular adhesion molecule 1 (ICAM-1), vascular cell adhesion molecule 1 (VCAM-1), and E-selectin. The serum concentrations of these three factors were detected similarly to sCD40L levels, using the ELISA method.

\section{Detection of C-reactive protein}

Immunoturbidimetry was used to detect $\mathrm{C}$-reactive protein (CRP) levels; this procedure was carried out in strict accordance with the immunoturbidimetry kit instructions. A volume of $15 \mu \mathrm{L}$ was taken from each serum sample and placed in a test tube. An amount of $15 \mu \mathrm{L}$ of CRP calibration solution and $15 \mu \mathrm{L}$ buffer solution were then placed in respective test tubes. The contents of these three tubes were then combined, mixed evenly with $350 \mathrm{~mL}$ of buffer, and incubated at $37^{\circ} \mathrm{C}$ for 5 minutes. The optical density value at 340 and $700 \mathrm{~nm}$ was then determined by spectrophotometry.

\section{Detection of serum MMP-9}

ELISA kits with a sensitivity of $2 \mathrm{ng} / \mathrm{mL}$ were used to detect serum MMP-9 concentrations. Prior to this assay being carried out, ELISA kits were placed at room temperature $\left(20-25^{\circ} \mathrm{C}\right)$ for 30 minutes. Using double distilled water, the concentrated washing solution was diluted to $1,000 \mathrm{~mL}$. The serum samples for use in this assay were then thawed and diluted with $1 \mathrm{~mL}$ of standard dilution buffer. After mixing evenly, we produced a high concentration standard solution of $200 \mathrm{ng} / \mathrm{mL}$, which we then diluted to produce lower concentration standards; the final standard sample had a concentration of just above $0 \mathrm{pg} / \mathrm{mL}$. These standard concentration samples were then placed in 8-well plates, and $100 \mu \mathrm{L}$ samples were added to their corresponding reaction wells. One well was left empty. The solutions in the wells were then mixed evenly and incubated for 90 minutes at $37^{\circ} \mathrm{C}$. To detect MMP-9 levels, $3 \mathrm{~mL}$ Biotin diluent was added to the 


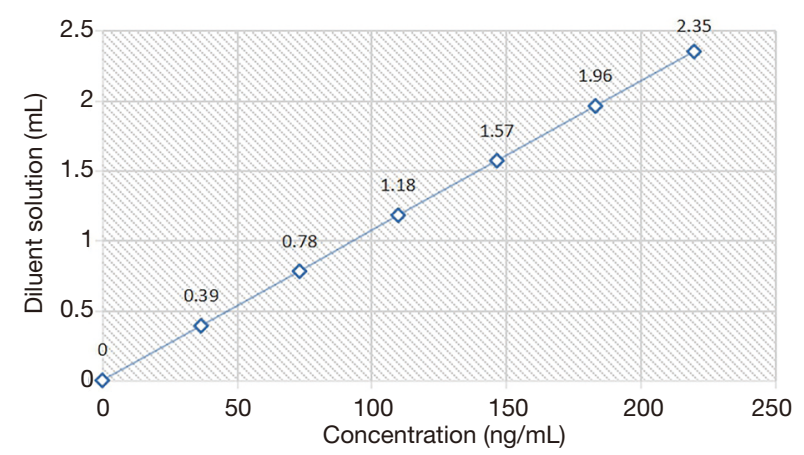

Figure 1 Standard for detection of serum MMP-9 concentration.

Table 1 Comparison of serum MMP-9 concentrations between the two groups $(\bar{x} \pm \mathrm{s})$

\begin{tabular}{lcc}
\hline Groups & N & MMP-9 concentration $(\mathrm{ng} / \mathrm{mL})$ \\
\hline CSFP group & 80 & $11.54 \pm 1.92$ \\
NCF group & 80 & $9.24 \pm 2.61$ \\
$\mathrm{t}$ & - & 5.372 \\
$\mathrm{P}$ & - & 0.047 \\
\hline
\end{tabular}

MMP-9, matrix metalloproteinase-9; CSFP, coronary slow flow phenomenon; NCF, normal coronary flow.

Table 2 Comparison of serum sCD40L concentrations between the two groups $(\bar{x} \pm \mathrm{s})$

\begin{tabular}{lcc}
\hline Groups & $\mathrm{N}$ & sCD40L concentration $(\mathrm{ng} / \mathrm{mL})$ \\
\hline CSFP group & 80 & $14.54 \pm 3.02$ \\
NCF group & 80 & $5.17 \pm 1.59$ \\
$\mathrm{t}$ & - & 10.217 \\
$\mathrm{P}$ & - & 0.025 \\
\hline
\end{tabular}

SCD40L, soluble cluster of differentiation 40 ligand; CSFP, coronary slow flow phenomenon; NCF, normal coronary flow.

corresponding samples, which were then washed 5 times with washing solution, mixed again, and incubated at $37^{\circ} \mathrm{C}$ for 1 hour. Chromogenic solution was added to each well, then the plates were incubated at $37^{\circ} \mathrm{C}$ for 20 minutes in a dark environment. After adding terminating solution, the chromogenic solution was mixed evenly in the wells, and optical density measurements were obtained using a $450 \mathrm{~nm}$ filter.

\section{Observation index}

The aims of this study were as follows: (I) to compare serum
sCD40L and MMP-9 levels between the two groups; (II) to compare serum levels of adhesion molecules, including VCAM-1, ICAM-1, and E-selectin, and CRP serum levels between the two groups; (III) to analyze the correlation between sCD40L levels and adhesion molecule levels between the two groups; and (IV) to compare CTFC results between the two groups. The CTFC results included circumflex branch, right coronary artery, and anterior descending branch data, as well as mean CTFC data for the coronary artery. The mean CTFC of the coronary artery was found using the following formula: mean CTFC of the coronary artery $=($ circumflex branch $\mathrm{CTFC}+$ right coronary artery CTFC + anterior descending branch CTFC)/common artery.

\section{Statistical analysis}

Data were analyzed using SPSS20.0 statistical analysis software. Measurement data are expressed as mean \pm standard deviation $(\bar{x} \pm \mathrm{s})$ and analyzed using the $t$-test. Count data are expressed as percentages and analyzed using the chi-squared test. Differences of $\mathrm{P}<0.05$ were considered statistically significant.

\section{Results}

\section{Comparison of serum sCD40L and MMP-9 levels between} the two groups

We found that serum MMP-9 (Figure 1) and sCD40L levels in the CSFP group were significantly higher than in the NCF group $(\mathrm{P}<0.05)$. See Tables 1 and 2.

\section{Comparison of serum sCD40L, adhesion molecules, and CRP levels between the two groups}

We found that serum levels of sCD40L, the cell adhesion molecules VCAM-1, ICAM-1, and E-selectin, and CRP were significantly higher in the CSFP group compared with the NCF group $(\mathrm{P}<0.05)$. See Table 3 .

\section{Comparison of the correlations between sCD4OL and adbesion molecules between the two groups}

We found positive correlations in the CSFP group between sCD40L and the adhesion molecules VCAM-1, ICAM-1, and E-selectin, as well as CRP. No such correlations were observed in the NCF group. Differences of $\mathrm{P}>0.05$ were 
Table 3 Comparison of serum sCD40L, adhesion molecule, and CRP concentrations between the two groups $\left(\bar{x}_{ \pm s}\right)$

\begin{tabular}{|c|c|c|c|c|c|c|}
\hline Groups & $\mathrm{N}$ & $\mathrm{sCD} 40 \mathrm{~L}(\mathrm{ng} / \mathrm{mL})$ & VCAM-1 (ng/mL) & ICAM-1 (ng/mL) & E-selectin (ng/mL) & $\mathrm{CRP}(\mathrm{mg} / \mathrm{L})$ \\
\hline NCF group & 80 & $5.17 \pm 1.59$ & $635.98 \pm 184.52$ & $220.42 \pm 78.74$ & $38.17 \pm 8.79$ & $5.19 \pm 1.19$ \\
\hline $\mathrm{t}$ & - & 10.197 & 20.375 & 15.492 & 13.371 & 12.735 \\
\hline$P$ & - & 0.034 & 0.010 & 0.029 & 0.042 & 0.037 \\
\hline
\end{tabular}

SCD40L, soluble cluster of differentiation 40 ligand; CRP, C-reactive protein; VCAM-1, vascular cell adhesion molecule 1; ICAM-1, intercellular adhesion molecule 1; CSFP, coronary slow flow phenomenon; NCF, normal coronary flow.

Table 4 Comparison of the correlations between serum levels of sCD40L and different adhesion molecules between the two groups $(\bar{x} \pm s)$

\begin{tabular}{|c|c|c|c|c|}
\hline Groups & VCAM-1 (ng/mL) & ICAM-1 (ng/mL) & E-selectin (ng/mL) & $\mathrm{CRP}(\mathrm{mg} / \mathrm{L})$ \\
\hline r & 0.872 & 0.729 & 0.874 & 0.778 \\
\hline $\mathrm{P}$ & 0.023 & 0.038 & 0.029 & 0.037 \\
\hline \multicolumn{5}{|l|}{ NCF } \\
\hline$P$ & 0.674 & 0.502 & 0.591 & 0.536 \\
\hline
\end{tabular}

Differences of $\mathrm{P}>0.05$ were not found to be statistically significant, while differences of $\mathrm{P}<0.05$ were found to be statistically significant. SCD40L, soluble cluster of differentiation 40 ligand; CRP, C-reactive protein; VCAM-1, vascular cell adhesion molecule 1; ICAM-1, intercellular adhesion molecule 1; CSFP, coronary slow flow phenomenon; NCF, normal coronary flow.

Table 5 Comparison of CTFCs between the two groups ( $\bar{x} \pm \mathrm{s}$, frames)

\begin{tabular}{lccccc}
\hline Index & $\mathrm{N}$ & Circumflex branch CTFC & Right coronary artery CTFC & Anterior descending branch CTFC & Mean coronary artery CTFC \\
\hline CSFP group & 80 & $34.92 \pm 12.11$ & $32.18 \pm 10.29$ & $37.39 \pm 16.91$ & $32.15 \pm 9.73$ \\
NCF group & 80 & $17.18 \pm 3.35$ & $16.39 \pm 3.56$ & $17.19 \pm 3.40$ & $16.49 \pm 3.38$ \\
t & - & 10.431 & 10.378 & 12.475 & 10.179 \\
$\mathrm{P}$ & - & 0.037 & 0.039 & 0.025 & 0.041 \\
\hline
\end{tabular}

Differences of $\mathrm{P}<0.05$ were found to be statistically significant. CTFC, corrected TIMI frame count; CSFP, coronary slow flow phenomenon; NCF, normal coronary flow.

not found to be statistically significant, while differences of $\mathrm{P}<0.05$ were found to be statistically significant. See Table 4 .

\section{Comparison of CTFCs between the two groups}

We found that the circumflex branch, the right coronary artery, and the anterior descending branch CTFCs, as well as the mean coronary artery CTFC, in the CSFP group were significantly higher compared with the CTFCs of the NCF group $(\mathrm{P}<0.05)$. See Table 5 .

\section{Discussion}

CSF is a significant angiographic complication (15-17) that is usually characterized by an overlap between the injection of contrast medium in a coronary angiography and when this dye passes through the coronary artery (18). CSF is a common disease (19) that is more easily recognized in patients with acute coronary syndrome $(20,21)$. While the etiology and pathological mechanisms of CSF are not currently well understood (22), there are several theories as 
to the pathology of this condition. These theories include endothelial dysfunction (23), inflammatory reaction (24), microangiopathy (25), early clinical manifestations of coronary atherosclerosis (26), an imbalance of vasomotor secretions (27), and abnormal platelet function and morphology (28). Most CSF patients experience recurrent chest pain, which reduces their quality of life and also has implications for their health (29).

In this study, we retroactively analyzed patients suspected of having coronary heart disease. We found that CSFP group patients had significantly higher levels of MMP9 compared with NCF group patients $(\mathrm{P}<0.05)$, and we found a positive correlation between serum MMP-9 levels and CTFC. CSFP group patients were also found to have significantly higher levels of sCD40L, VCAM-1, ICAM-1, E-selectin, and CRP compared with NCF group patients $(\mathrm{P}<0.05)$. Positive correlations were found between sCD40L and the adhesion molecules VCAM-1, ICAM-1, and E-selectin, as well as CDP, in the CSFP group. No such correlations were found in the NCF group. Additionally, the CTFC for the circumflex branch, right coronary artery, and anterior descending branch, as well as the mean CTFC for the coronary artery, were significantly higher in the CSFP group compared with the NCF group $(\mathrm{P}<0.05)$. This was consistent with all other results obtained in this study.

These results support the theory that inflammation is involved in the pathology of CSF due to the increased levels of serum MMP-9 observed in CSF patients. These increased MMP-9 levels may also predict the presence of atherosclerotic plaques in the coronary arteries. MMP-9 is additionally involved in breaking down the extracellular matrix of plaques, which leads to reduced stability of these structures. Increased MMP-9 levels are associated with a higher probability of myocardial ischemia and acute coronary syndrome. In addition to the increased MMP-9 levels, sCD40L levels were also increased in CSF patients, and a positive correlation was found between sCD40L and adhesion molecules. This suggests that sCD40L may increase the expression of adhesion molecules, which in turn may lead to the development of CSF.

\section{Acknowledgments}

Funding: None.

\section{Footnote}

Reporting Checklist: The authors have completed the MDAR reporting checklist. Available at http://dx.doi.org/10.21037/ apm-20-2271

Data Sharing Statement: Available at http://dx.doi. org/10.21037/apm-20-2271

Conflicts of Interest: All authors have completed the ICMJE uniform disclosure form (available at Article Information: http://dx.doi.org/10.21037/apm-20-2271). The authors have no conflicts of interest to declare.

Ethical Statement: The authors are accountable for all aspects of the work in ensuring that questions related to the accuracy or integrity of any part of the work are appropriately investigated and resolved. This study was approved by the Ethics Committee of Nanjing Jiangbei People's Hospital (IRB-TY-2016-78) and all participants signed the informed consent. All procedures performed in this study involving human participants were in accordance with the Declaration of Helsinki (as revised in 2013).

Open Access Statement: This is an Open Access article distributed in accordance with the Creative Commons Attribution-NonCommercial-NoDerivs 4.0 International License (CC BY-NC-ND 4.0), which permits the noncommercial replication and distribution of the article with the strict proviso that no changes or edits are made and the original work is properly cited (including links to both the formal publication through the relevant DOI and the license). See: https://creativecommons.org/licenses/by-nc-nd/4.0/.

\section{References}

1. Demirci E, Celik O, Kalcik M, et al. Evaluation of homocystein and asymmetric dimethyl arginine levels in patients with coronary slow flow phenomenon. Interv Med Appl Sci 2019;11:89-94.

2. Carvalho FP, Azevedo CF. Coronary Slow Flow Phenomenon - Adding Myocardial Fibrosis to the Equation. Arq Bras Cardiol 2020;114:552-3.

3. Sadamatsu K, Koga Y, Tashiro H. Long-Term Follow-up of Patients with Coronary Slow Flow Phenomenon. Am J Cardiovasc Drugs 2018;18:73-4.

4. Karimianpour A, Maran A. Advances in Coronary NoReflow Phenomenon-a Contemporary Review. Curr Atheroscler Rep 2018;20:44.

5. Xing Y, Shi J, Yan Y, et al. Subclinical myocardial dysfunction in coronary slow flow phenomenon: 
Identification by speckle tracking echocardiography. Microcirculation 2019;26:e12509.

6. Scarpone M, Cenko E, Manfrini O. Coronary No-Reflow Phenomenon in Clinical Practice. Curr Pharm Des 2018;24:2927-33.

7. Liu CL, Xue ZQ, Gao SP, et al. The Relationship between Interleukin-6 Promotor Polymorphisms and Slow Coronary Flow Phenomenon. Clin Lab 2016;62:947-53.

8. Ghaffari S, Tajlil A, Aslanabadi N, et al. Clinical and laboratory predictors of coronary slow flow in coronary angiography. Perfusion 2017;32:13-9.

9. Sanati H, Kiani R, Shakerian F, et al. Coronary Slow Flow Phenomenon Clinical Findings and Predictors. Res Cardiovasc Med 2016;5:e30296.

10. Sucu M, Ucaman B, Altunbas G. Early repolarization pattern in the coronary slow flow phenomenon. Scand Cardiovasc J 2018;52:108-12.

11. Zhao ZW, Ren YG, Liu J. Low Serum Adropin Levels are Associated with Coronary Slow Flow Phenomenon. Acta Cardiol Sin 2018;34:307-12.

12. Lai X, Jiang B, Liu J, et al. Generation of an induced pluripotent stem cell line (SYSUi002-A) from a patient with coronary slow flow phenomenon. Stem Cell Res 2019;41:101646.

13. Sanghvi S, Mathur R, Baroopal A, et al. Clinical, demographic, risk factor and angiographic profile of coronary slow flow phenomenon: A single centre experience. Indian Heart J 2018;70 Suppl 3:S290-4.

14. Masoumi M, Mohammadi K. Coronary Slow Flow Phenomenon and Atrioventricular Block: A Case Report. J Tehran Heart Cent 2017;12:85-7.

15. Candemir M, Sahinarslan A, Yazol M, et al. Determination of Myocardial Scar Tissue in Coronary Slow Flow Phenomenon and The Relationship Between Amount of Scar Tissue and Nt-ProBNP. Arq Bras Cardiol 2020;114:540-51.

16. Mehta HH, Morris M, Fischman DL, et al. The Spontaneous Coronary Slow-Flow Phenomenon: Reversal by Intracoronary Nicardipine. J Invasive Cardiol 2019;31:42-5.

17. Zhu X, Shen H, Gao F, et al. Clinical Profile and Outcome in Patients with Coronary Slow Flow Phenomenon.
Cardiol Res Pract 2019;2019:9168153.

18. He W, Huang Y, Zhang Y, et al. Cardiac rehabilitation therapy for coronary slow flow phenomenon. Herz 2020;45:468-74.

19. Wang L, Wang HN, Zu XL. Relationship between plasma miR-126 and coronary slow flow phenomenon. Zhonghua Yi Xue Za Zhi 2019;99:1323-7.

20. Çelik O, Demirci E, Aydin M, et al. Evaluation of ghrelin levels and endothelial functions in patients with coronary slow flow phenomenon. Interv Med Appl Sci 2017;9:154-9.

21. Li Y, Fang F, Ma N, et al. Feasibility Study of Transthoracic Echocardiography for Coronary Slow Flow Phenomenon Evaluation: Validation by Coronary Angiography. Microcirculation 2016;23:277-82.

22. Sheng X, Ding S, Ge H, et al. Intracoronary infusion of alprostadil and nitroglycerin with targeted perfusion microcatheter in STEMI patients with coronary slow flow phenomenon. Int J Cardiol 2018;265:6-11.

23. Yasri S, Wiwanitkit V. Interleukin-1 gene cluster polymorphisms associated with coronary slow flow phenomenon. Anatol J Cardiol 2018;19:229.

24. Mutluer F O, Ural D, Gungor B, et al. Association of Interleukin-1 Gene cluster polymorphisms with coronary slow flow phenomenon. Anatol J Cardiol 2018;19:34-41.

25. Mutluer FO, Ural D, Gungor B, et al. Association of Interleukin-1 Gene cluster polymorphisms with coronary slow flow phenomenon. Anatol J Cardiol 2018;19:34-41.

26. Yasri S, Wiwanitkit V. Interleukin-1 gene cluster polymorphisms associated with coronary slow flow phenomenon. Anatol J Cardiol 2018;19:229.

27. Chacko J, Brar G, Mundlapudi B, et al. Papillary Muscle Dysfunction Due to Coronary Slow-Flow Phenomenon Presenting with Acute Mitral Regurgitation and Unilateral Pulmonary Edema. Indian J Crit Care Med 2018;22:806-8.

28. Su Q, Yang H, Li L. Circulating miRNA-155 as a Potential Biomarker for Coronary Slow Flow. Dis Markers 2018;2018:6345284.

29. Jin Z, Tan Q, Sun B. Telmisartan ameliorates vascular endothelial dysfunction in coronary slow flow phenomenon (CSFP). Cell Biochem Funct 2018;36:18-26.
Cite this article as: Zhang X, Ding J, Xia S. A preliminary study of MMP-9 and sCD40L in patients with coronary slow flow. Ann Palliat Med 2021;10(1):657-663. doi: 10.21037/apm-202271 